\title{
A novel high-amylose barley cultivar (Hordeum vulgare var. Himalaya 292) lowers plasma cholesterol and alters indices of large-bowel fermentation in pigs
}

\author{
Anthony R. Bird*, Michelle Jackson, Roger A. King, Debra A. Davies, Sylvia Usher and \\ David L. Topping \\ CSIRO Health Sciences and Nutrition, PO Box 10041, Kintore Avenue, Adelaide BC 5000, Australia
}

(Received 3 February 2004 - Revised 28 June 2004 - Accepted 30 June 2004)

\begin{abstract}
Hordeum vulgare var. Himalaya 292 is a new barley cultivar with altered starch synthesis and less total starch but more amylose, resistant starch (RS) and total and soluble NSP including $\beta$-glucan. To determine its nutritional potential, young pigs were fed diets containing stabilised wholegrain flours from either Himalaya 292, Namoi (a commercial barley), wheat bran or oat bran at equivalent dietary NSP concentrations for $21 \mathrm{~d}$. Serum total cholesterol was significantly lowered by the Himalaya 292 diet relative to wheat bran, indicating that Himalaya 292 retained its hypocholesterolaemic potential. In all groups SCFA concentrations were highest in the proximal colon and decreased towards the rectum. Digesta $\mathrm{pH}$ was lowest in the proximal colon and highest in the distal colon. Large-bowel and faecal $\mathrm{pH}$ were significantly lower in the pigs fed the barley and oat diets, indicating greater bacterial fermentation. Caecal and proximal colonic pH was lowest and SCFA pools highest in the pigs fed Himalaya 292. Total and individual SCFA were lowest in the mid- and distal colon of the pigs fed Himalaya 292 or oat bran. These data suggest the presence of more RS in Himalaya 292 and suggest that its fermentation was rapid relative to transit. Differences in faecal and large-bowel anaerobic, aerobic, coliform and lactic acid bacteria were relatively small, indicating a lack of a specific prebiotic action. These data support the potential of this novel barley cultivar to improve health through plasma cholesterol reduction and increased large-bowel SCFA production.
\end{abstract}

Bacteria: Dietary fibre: Plasma cholesterol: Starch: Barley

Plant foods and their carbohydrate components have wellestablished roles in the management and prevention of non-infectious chronic illnesses. Wholegrain cereal consumption has been linked to a lowered risk of certain cancers and of CHD (Marquart et al. 2002; Truswell, 2002). These cereals are high in starch and dietary fibre. The latter comprises largely NSP (Spiller, 2001), and NSP-rich foods are well-established laxating agents (Borum, 2001). Soluble NSP, such as $\beta$-glucan and those of psyllium, have been shown to lower serum cholesterol (Brown et al. 1999; Anderson et al. 2000; Jenkins et al. 2002), an established risk factor for early-onset CHD. NSP resist human intestinal digestive enzymes, which helps to explain their effectiveness in increasing faecal bulk, an important component of their laxative action (Topping \& Clifton, 2001). Resistant starch (RS) is that fraction of starch and the products of its digestion that are not absorbed in the small intestine of healthy human individuals and enter the large bowel (Asp, 1992). In the latter viscus both RS and a variable fraction of NSP are fermented by the microflora (Topping \& Clifton, 2001). SCFA are major products of this fermentation and they promote several important aspects of large-bowel function, such as the stimulation of fluid and electrolyte absorption and the modulation of muscular contraction and visceral perfusion (Topping \& Clifton, 2001). It appears that the intakes and fermentability of NSP are insufficient to support the bacterial colonisation of the normal human large bowel. This is the, so-called, 'carbohydrate gap', which is filled by other substrates including RS (Stephen et al. 1983).

$\mathrm{RS}$ is a modest faecal bulking agent and some studies suggest that a combination of NSP and RS is especially useful for the promotion of large-bowel health (Govers et al. 1999). The modification of foods to enhance the content and action of RS and NSP is a recognised means of effecting dietary change at the population level to improve public health. A novel cultivar of a hull-less barley (Hordeum vulgare var. Himalaya 292) with a specific defect in starch synthesis has been identified recently and grown in quantity (Morell et al. 2003). This modification occurs in starch synthase IIa (EC 2.4.1.21) and results in a shrunken grain containing as little as $18 \%$ starch, of which approximately $70 \%$ is present as amylose, compared with approximately 50 and $25 \%$ respectively for its Himalaya parent (Morell et al. 2003).

\footnotetext{
Abbreviations: RS, resistant starch; TAG, triacylglycerol.

* Corresponding author: Dr A. R. Bird, fax +6188303 8899, email tony.bird@csiro.au
} 
Himalaya 292 grain contains approximately $25 \%$ total NSP, and $10 \% \beta$-glucan (Topping et al. 2003). These compositional changes suggested that Himalaya 292 would be high in RS (Morell et al. 2003), and this was confirmed in a feeding trial in rats, which showed substantially greater caecal starch in rats fed Himalaya 292 compared with wheat bran, oat bran and a commercial barley cultivar (Bird et al. 2004). The rat has limitations as an experimental model for human plasma lipid metabolism and largebowel carbohydrate digestion and fermentation (Roe et al. 1996). In the present study, therefore, we sought to explore the nutritional properties of Himalaya 292 in a more relevant species, the pig. Specifically we sought to determine whether the processed grain lowered plasma cholesterol relative to wheat bran. We also assessed whether there were any changes in faecal and large-bowel SCFA and microflora.

\section{Materials and methods}

\section{Care of animals}

The study was carried out under contract at the Pig Metabolism Unit of the Victorian Institute of Animal Science at Werribee, Victoria, Australia. The study was approved by the relevant institutional animal experimentation committees and conformed to published guidelines (National Health and Medical Research Council, 1997).

\section{Diets, feeding and experimental design}

Twenty-eight male crossbred pigs (about 9 weeks of age) with initial live weights averaging $24 \mathrm{~kg}$ were used in a randomised complete block design experiment. They were housed in individual galvanised steel pens with concrete floors in a pig grower shed and were allowed $7 \mathrm{~d}$ to adapt to their surroundings and feeding regimen before starting the experiment. During this adjustment phase (designated week 1), all pigs were maintained on the wheat-bran control diet (Table 1), after which they were blocked on live weight and assigned randomly within blocks to one of four dietary treatment groups, each of seven animals for a period of 3 weeks (designated weeks 2, 3 and 4). The experimental diets were formulated to supply equal quantities of fat, protein and carbohydrate in the proportions 8,20 and $60 \%$ respectively. The fibre content (as NSP) was set at $75 \mathrm{~g} / \mathrm{kg}$ diet and was supplied as wheat bran (wheat-bran diet; control), Himalaya 292 wholemeal flour, standard hull-less barley wholemeal flour (Namoi) or a commercial oat-bran product (Oat Gold $^{\mathrm{TM}}$; oat-bran diet). The proximate composition of Himalaya 292 and the other cereal ingredients has been reported previously (Bird et al. 2004). All diets were balanced for their macronutrient content by changing the proportions of the other ingredients. The starch component of the control diet was provided by a pre-gelatinised lowamylose starch and this same product was used where necessary to balance the starch level in the other diets.

Pigs had free access to fresh water, and diets were mealfed at $70 \mathrm{~g} / \mathrm{kg}$ live weight ${ }^{0.75}$. They were weighed weekly before the morning feeding and food intake adjusted accordingly. Dry rations were mixed with water in a 2:1 ratio (w/w) and offered twice daily as a morning and evening meal. Cooked minced meat was weighed separately and then mixed with the wet diet. Wheat bran with a particle size of 2-3 mm and suitable for human consumption was supplied by Bartlett Grains (Port Adelaide, South Australia, Australia). Pre-gelatinised low-amylose starch (B012XF) was obtained from Penford Australia Pty Ltd (Lane Cove, NSW, Australia); Namoi and Himalaya 292 were obtained from CSIRO Plant Industry (Black Mountain, ACT, Australia) and were heat stabilised batch-wise using moist heat at $100-120^{\circ} \mathrm{C}$, with steam delivered at $110 \mathrm{kPa}$ for $12 \mathrm{~min}$, followed by vacuum at $-80 \mathrm{kPa}$ for 20-30 min. Oat Gold ${ }^{\mathrm{TM}}$ was supplied by The Uncle Toby's Company (Wahgunyah, Victoria, Australia).

Table 1. Ingredient composition of control and experimental diets $(\mathrm{g} / \mathrm{kg})$

\begin{tabular}{|c|c|c|c|c|}
\hline \multirow[b]{2}{*}{ Ingredient } & \multicolumn{4}{|c|}{ Diet } \\
\hline & Wheat bran & Namoi & Himalaya 292 & Oat bran \\
\hline Wheat bran & 162 & & & \\
\hline Namoi & & 608 & & \\
\hline Himalaya 292 & & & 256 & \\
\hline Oat Gold $^{\mathrm{TM}}$ & & & & 287 \\
\hline Cooked minced beef & 229 & 139 & 194 & 186 \\
\hline Skimmed milk powder & 159 & 97 & 135 & 129 \\
\hline Starch* $^{*}$ & 363 & 62 & 341 & 329 \\
\hline $\mathrm{CaHPO}_{4} \cdot 2 \mathrm{H}_{2} \mathrm{O}$ & $4 \cdot 4$ & $4 \cdot 4$ & 4.4 & 4.4 \\
\hline Sucrose & 44 & 44 & 39 & 44 \\
\hline Safflower-seed oil & 34 & 40 & 26 & 15 \\
\hline $\mathrm{NaCl}$ & $2 \cdot 2$ & $2 \cdot 2$ & $2 \cdot 2$ & $2 \cdot 2$ \\
\hline Vitamins and minerals & 1.5 & 1.5 & 1.5 & 1.5 \\
\hline Chromic oxide & 1.0 & $1 \cdot 0$ & $1 \cdot 0$ & 1.0 \\
\hline
\end{tabular}

* Pre-gelatinised low-amylose starch (B012XF; Penford Australia Pty Ltd, Lane Cove, NSW, Australia).

†Pharmamix P169 (Propharma Australia Pty Ltd, Dandenong, Victoria, Australia), which contained (per kg $\mathrm{mix}$ ): retinyl acetate, $1.5 \mathrm{~g}$; cholecalciferol, $25 \mathrm{mg}$; $\alpha$-tocopherol, $20 \mathrm{~g}$; riboflavin, $2 \mathrm{~g}$; cyanocobalamin, $7.5 \mathrm{mg}$; calcium pantothenate, $5.6 \mathrm{~g}$; biotin, $50 \mathrm{mg}$; nicotinamide, $10 \mathrm{~g}$; menadione, $1 \mathrm{~g} ; \mathrm{FeSO}_{4} .7 \mathrm{H}_{2} \mathrm{O}, 50 \mathrm{~g} ; \mathrm{MnO}_{2}$, $10 \mathrm{~g} ; \mathrm{ZnO}, 50 \mathrm{~g} ; \mathrm{CuSO}_{4} .7 \mathrm{H}_{2} \mathrm{O}, 5 \mathrm{~g} ; \mathrm{CoSO}_{4}, 0.25 \mathrm{~g} ; \mathrm{KI}, 0.5 \mathrm{~g} ; \mathrm{Na}_{2} \mathrm{SeO}_{4}, 0.1 \mathrm{~g}$; antioxidant, $31 \mathrm{~g}$ (Oxicap E2; Novus Nutrition, Melbourne, Australia). 


\section{Sampling and analytical procedures}

Faecal samples were collected during each week of the study. Freshly voided stools were frozen for subsequent analyses of SCFA, moisture and $\mathrm{pH}$. Faecal samples for bacteriological enumeration were diluted 8-fold with aqueous storage medium (buffered peptone $(20 \mathrm{~g} / \mathrm{l})$, lab-lemco powder $(20 \mathrm{~g} / \mathrm{l})$ and $20 \%(\mathrm{v} / \mathrm{v})$ glycerol) and frozen $\left(-20^{\circ} \mathrm{C}\right)$. For analyses, suspensions were thawed at $4^{\circ} \mathrm{C}$ and further serially diluted in pre-reduced buffered peptone (buffered peptone (20 g/l; Oxoid, Australia Pty Ltd, West Heidelberg, Victoria, Australia), $0.5 \%$ cysteine $\mathrm{HCl}$ and $0.1 \%$ Tween 80). Portions $(100 \mu \mathrm{l})$ of the appropriate dilutions were inoculated in duplicate onto plates containing Bifidus blood (Pachenari et al. 2001), Rogosa (Oxoid), Columbia blood (Oxoid) and Chromogenic Escherichia coli-coliform (Oxoid) media for the selective enumeration of Bifidobacteria, Lactobacilli, total anaerobes, E. coli, total coliforms, and total aerobes respectively. Plates were incubated at $37^{\circ} \mathrm{C}$ under anaerobic conditions using Anaerogen Compact (Oxoid) for a period of $5 \mathrm{~d}$ for Bifidus blood and Columbia blood plates and $3 \mathrm{~d}$ for Rogosa plates. Chromogenic plates were incubated at $37^{\circ} \mathrm{C}$ under aerobic conditions for $24 \mathrm{~h}$. Colonies characteristic of each bacterial group were then counted visually and the concentration calculated as colony-forming units/g wet weight.

At the completion of the treatment period, and about $16 \mathrm{~h}$ after the pigs had been fed their final meal the previous evening, they were weighed and anaesthetised with halothane. The abdominal cavity was then opened and blood was withdrawn from the abdominal aorta and serum prepared and stored for the later analysis of lipids. Pigs were then euthanased by an intracardial injection of an overdose of barbiturate. The entire gastrointestinal tract was tied off immediately, excised and the large bowel and small intestine separated and their length measured. The caecum and colon were ligated and the latter divided into three segments of equal length while the small intestine was divided into ten segments of equal length. Digesta from each of the smalland large-intestinal segments was extruded and weighed. The colon and caecum, empty of contents, were blotted dry and weighed. Samples of digesta from the proximal colon were collected using aseptic techniques and diluted 1:9 (w/v) in storage medium and bacteria enumerated as described for faeces. Additional colonic digesta samples were stored at $-20^{\circ} \mathrm{C}$ for later determination of $\mathrm{DM}$ and $\mathrm{pH}$ using standard procedures. Faecal and digesta SCFA were isolated by low-temperature vacuum microdistillation and quantified by GLC (Bird et al. 2000b). Briefly, frozen faecal and digesta samples were thawed at $4^{\circ} \mathrm{C}$ and a sub-sample diluted with heptanoic acid as internal standard, centrifuged, acidified and distilled under vacuum and SCFA in the distillates measured by GLC. Total cholesterol, HDL-cholesterol, and triacylglycerol (TAG) were measured in serum using commercial kits (Roche Diagnostics, Mannheim, Germany) and a Cobas-Bio centrifugal analyser (Roche, Basel, Switzerland).

\section{Statistical methods}

Statistical evaluations of the data were performed by twoway ANOVA using the general linear model procedure of SAS (version 8.02; Statistical Analytical Systems Institute Inc., Cary, NC, USA). The model included diet and weight block as sources of variation. When significant values were detected for diet $(F$ value $P<0.05)$, differences between individual means were then analysed by the protected difference procedure. Data are shown as least squares means and pooled standard errors of the least squares means (SEM). Where there is a missing value this is noted in the Tables and the SEM is weighted to allow for this change. Values in any Table column with unlike superscript letters were significantly different $(P<0 \cdot 05)$. For counts of bacteria, $\log _{10}$ transformation of the data was performed before the statistical determination of treatment effects. In one instance (faecal bifidobacteria numbers), analysis showed a significant difference between groups at week 1 . In this instance, analysis of the values was conducted with initial values as a covariate.

\section{Results}

\section{Feed intake and body-weight gain}

All diets were accepted and all food was eaten promptly on presentation. The amount of food offered was set as a constant fraction of body weight and there were no significant differences in body weight at the beginning of the experiment or at any point throughout the trial. Mean initial body weight for all groups combined was 24.5 (pooled SEM 0.2$) \mathrm{kg}$ and mean final body weight was 32.0 (pooled SEM 0.5) $\mathrm{kg}$.

\section{Serum lipids}

The mean concentration of serum total cholesterol in the pigs fed Himalaya 292 was significantly lower than in the pigs fed wheat bran. The mean concentration in the pigs fed oat bran was similar to that in the pigs fed Himalaya 292 , but this was not significantly different from wheat bran; the mean concentration in the pigs fed Namoi was intermediate to those of wheat bran and Himalaya 292 (Table 2). HDL concentrations did not differ between groups so this difference was attributable entirely to a lowering of VLDL- + intermediate-density lipoprotein- + LDL-cholesterol (calculated by difference). Serum TAG were unaffected by diet (Table 2).

\section{Faecal pH and short-chain fatty acids}

There were no significant differences in faecal $\mathrm{pH}$ between groups at the start of the feeding period (week 1; data not shown). Values did not change significantly throughout the study in the pigs fed wheat bran but $\mathrm{pH}$ was significantly (and equally) lower in the other groups at week 4 (Table 3). There were no significant differences between groups for faecal total and individual SCFA concentrations at the start of the study and at week 4 (Table 3). 
Table 2. Serum lipids in pigs after consumption of experimental and wheat-bran (control) diets for 3 weeks (seven pigs per diet) ${ }^{*}$

(Mean values and pooled standard errors of the mean)

\begin{tabular}{lcccr}
\hline & & \multicolumn{2}{c}{ Lipid concentration (mmol/l) } \\
\cline { 3 - 5 } Diet & Total cholesterol & VLDL- + LDL- + IDL-cholesterol & HDL-cholesterol & TAG \\
\hline Wheat bran & $3.06^{\mathrm{a}}$ & $1.79^{\mathrm{a}}$ & 1.27 & 0.79 \\
Namoi & $2.87^{\mathrm{a}, \mathrm{b}}$ & $1.59^{\mathrm{a}, \mathrm{b}}$ & 1.28 & 0.90 \\
Himalaya 292 & $2.58^{\mathrm{b}}$ & $1.39^{\mathrm{b}}$ & 1.19 & 0.79 \\
Oat brant & $2.62^{\mathrm{a}, \mathrm{b}}$ & $1.42^{\mathrm{a}, \mathrm{b}}$ & 1.20 & 0.89 \\
Pooled SEM & 0.16 & 0.14 & 0.06 & 0.09 \\
\hline
\end{tabular}

IDL, intermediate-density lipoprotein; TAG, triacylglycerol.

${ }^{\mathrm{a}, \mathrm{b}}$ Mean values within a column with unlike superscript letters were significantly different $(P<0.05)$

${ }^{\star}$ For details of diets and procedures, see Table 1 and p. 608.

† Mean values for six pigs.

Table 3. $\mathrm{pH}$ and short-chain fatty acid concentrations in faeces of pigs after consumption of experimental or wheat-bran (control) diets for 3 weeks (seven pigs per diet) ${ }^{*}$

(Mean values and pooled standard errors of the mean)

\begin{tabular}{|c|c|c|c|c|c|}
\hline \multirow[b]{2}{*}{ Diet } & \multirow[b]{2}{*}{$\mathrm{pH}$} & \multicolumn{4}{|c|}{$\begin{array}{l}\text { Short-chain fatty acid } \\
\text { concentration }(\mathrm{mmol} / \mathrm{kg})\end{array}$} \\
\hline & & Acetate & Propionate & Butyrate & Total \\
\hline Wheat bran & $6 \cdot 84^{a}$ & $43 \cdot 1$ & $17 \cdot 7$ & 8.4 & 69.2 \\
\hline Namoi & $6 \cdot 54^{b}$ & $52 \cdot 0$ & 23.2 & $11 \cdot 2$ & $86 \cdot 3$ \\
\hline Himalaya 292 & $6 \cdot 49^{b}$ & 43.8 & $15 \cdot 7$ & 8.0 & 67.6 \\
\hline Oat bran & $6 \cdot 43^{b}$ & 39.7 & $16 \cdot 6$ & 8.9 & $65 \cdot 2$ \\
\hline Pooled SEM & 0.05 & 4.9 & 3.5 & 1.5 & $9 \cdot \overline{3}$ \\
\hline
\end{tabular}

\section{Faecal bacteria}

Faecal anaerobe numbers did not differ between groups at week 1 (data not shown) but were significantly lower in the pigs fed wheat bran than in those fed Himalaya 292 and oat bran at week 4 (Table 4). Faecal aerobe numbers were not significantly different between groups either at week 1 or at week 4 . There were no significant differences in the numbers of total coliforms and $E$. coli between groups at any sampling time (data not shown). In contrast there were significant effects of diet on faecal lactic acid bacteria. Faecal numbers of Lactobacilli were similar between groups at the initial sampling time but at week 4 numbers were significantly lower in the pigs fed Namoi compared with those fed wheat bran (Table 4). In contrast to all other major bacterial groups, Bifidobacteria numbers were significantly lower at week 1 in the pigs assigned to be fed Namoi compared with those assigned to be fed wheat bran (4.95 v. $7 \cdot 10$ colony-forming units/g, respectively; $P<0.01)$ and at week 4 compared with both wheat bran and Himalaya 292 (Table 4). This latter difference remained significant even when the data were analysed with the week 1 values as covariate.

\section{Intestinal length and weight, and digesta weight}

Neither the length nor the weight of small or large intestine free of content was affected by diet (data not shown). The wet weight of small-intestinal digesta was lowest in the pigs fed the Namoi diet and significantly higher in those fed oat bran with respective mean values of 340 and 448 (pooled SEM 35) g $(P<0.05)$. Values were 366 and $404 \mathrm{~g}$ for the wheat-bran and Himalaya 292 groups, respectively. These did not differ from each other or the other treatments. There were significant effects of diet on largebowel digesta with significantly more in the pigs fed wheat bran than in all other groups (Table 5). There was also a significant interaction between diet and sampling site, with more digesta in the mid- and distal colon of the pigs fed wheat bran than in those fed Himalaya 292 or oat bran. Digesta water content was unaffected by diet and fell significantly $(P<0.001)$ in all groups from approximately $86 \%$ in the caecum to $75 \%$ in the distal colon (data not shown).

Table 4. Bacteria numbers ( $\log _{10}$ colony-forming units/g) in faeces of pigs after consumption of experimental and wheat-bran (control) diets for 3 weeks

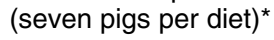

(Mean values and pooled standard errors of the mean)

\begin{tabular}{lcccc}
\hline Diet & Anaerobes & Aerobes & Lactobacilli & Bifidobacteria \\
\hline Wheat bran & $9.13^{\mathrm{a}}$ & 7.94 & $8.20^{\mathrm{a}}$ & $7.47^{\mathrm{a}}$ \\
Namoi & $9.23^{\mathrm{a}, \mathrm{b}}$ & 7.66 & $7.35^{\mathrm{b}}$ & $6.48^{\mathrm{b}}$ \\
Himalaya 292 & $9.44^{\mathrm{b}}$ & 8.00 & $8 \cdot 16^{\mathrm{a}, \mathrm{b}}$ & $7.51^{\mathrm{a}}$ \\
Oat bran & $9.44^{\mathrm{b}}$ & 8.05 & $7.49^{\mathrm{a}, \mathrm{b}}$ & $7.33^{\mathrm{a}, \mathrm{b}}$ \\
Pooled SEM & 0.07 & 0.14 & 0.27 & 0.29 \\
\hline
\end{tabular}

\footnotetext{
${ }^{a, b}$ Mean values within a column with unlike superscript letters were significantly different $(P<0.05)$.

${ }^{*}$ For details of diets and procedures, see Table 1 and p. 608.
} 
Table 5. Large-bowel digesta weight (g) of pigs after consumption of experimental or wheat-bran (control) diets for 3 weeks (seven pigs per diet)*

(Mean values and pooled standard errors of the mean)

\begin{tabular}{lccccc}
\hline & & & \multicolumn{3}{c}{ Colon } \\
\cline { 4 - 6 } Diet & Total & Caecum & Proximal & Mid & Distal \\
\hline Wheat bran & $772^{\mathrm{a}}$ & 128 & 307 & $203^{\mathrm{a}}$ & $132^{\mathrm{a}}$ \\
Namoi & $615^{\mathrm{b}}$ & 132 & $277 \dagger$ & $158^{\mathrm{a}, \mathrm{b}}$ & $101^{\mathrm{a}, \mathrm{b}}$ \\
Himalaya 292 & $620^{\mathrm{b}}$ & 142 & 299 & $112^{\mathrm{b}}$ & $68^{\mathrm{b}, \mathrm{c}}$ \\
Oat bran & $511^{\mathrm{b}}$ & 89 & 244 & $125^{\mathrm{b}}$ & $54^{\mathrm{c}}$ \\
Pooled SEM & 50 & 23 & 26 & 18 & 12 \\
\hline
\end{tabular}

${ }^{a, b, c}$ Mean values within a column with unlike superscript letters were significantly different $(P<0.05)$.

${ }^{*}$ For details of diets and procedures, see Table 1 and p. 608. † Mean value for six pigs.

\section{Large-intestinal $\mathrm{pH}$ and short-chain fatty acid concentrations and pools}

Concentrations of total caecal SCFA were highest, and $\mathrm{pH}$ values lowest, in the pigs fed Himalaya 292 and were significantly different from those of the pigs fed wheat bran (Tables 6 and 7). Similar differences in SCFA concentrations were seen in the proximal colon. There were no significant differences in the mid-colon but in the distal colon, total concentrations of SCFA were higher in the Namoi group than in the oat-bran or Himalaya 292 groups. Acetate had a regional concentration profile very similar to that of total SCFA. Thus, acetate was highest in the caecal digesta of the pigs fed Himalaya 292 and in the proximal colonic contents of those fed Namoi (Table 7). Caecal and proximal colonic propionate concentrations were significantly higher in the pigs fed Himalaya 292 than in the pigs fed wheat bran (Table 7). In the midcolon, the difference was significant only between wheat bran and Namoi. In the distal colon, concentrations were higher in the pigs fed Namoi than in all other groups, although this was statistically significant only for Himalaya 292 and oat bran. Concentrations of butyrate were highest in the caecum of the pigs fed Himalaya 292 but the difference was statically significant only against wheat bran (Table 7). There were no significant differences in concentration in the mid- or distal colon.

Table 6. Large-bowel digesta $\mathrm{pH}$ of pigs after consumption of experimental or wheat-bran (control) diets for 3 weeks (seven pigs per diet) ${ }^{\star}$

(Mean values and pooled standard errors of the mean)

\begin{tabular}{lclll}
\hline & & \multicolumn{3}{c}{ Colon } \\
\cline { 3 - 5 } Diet & Caecum & Proximal & Mid & Distal \\
\hline Wheat bran & $6 \cdot 40^{\mathrm{a}}$ & $6.61^{\mathrm{a}}$ & $6.86^{\mathrm{a}}$ & $6.86^{\mathrm{a}}$ \\
Namoi & $6 \cdot 11^{\mathrm{a}}$ & $6.37^{\mathrm{a}, \mathrm{b}}$ & $6.66^{\mathrm{b}}$ & $6.62^{\mathrm{b}}$ \\
Himalaya 292 & $5.57^{\mathrm{b}}$ & $6.09^{\mathrm{c}}$ & $6.52^{\mathrm{b}, \mathrm{c}}$ & $6.57^{\mathrm{b}}$ \\
Oat bran & $6.15^{\mathrm{a}}$ & $6.31^{\mathrm{b}, \mathrm{c}}$ & $6.43^{\mathrm{c}}$ & $6.54^{\mathrm{b}}$ \\
Pooled SEM & 0.13 & 0.09 & 0.07 & 0.04 \\
\hline
\end{tabular}

${ }_{\mathrm{a}, \mathrm{b}, \mathrm{c}}$ Mean values within a column with unlike superscript letters were significantly different $(P<0.05)$

* For details of diets and procedures, see Table 1 and p. 608

† Mean values for six pigs.
Concentration is a relatively limited indicator of largebowel SCFA status, as it gives no indication of their total availability. Pool (i.e. concentration $\times$ digesta volume) is a much better indicator. As expected from the concentration data, there were significant independent and interactive effects of diet and sampling site on large-bowel SCFA pools. Individual comparisons revealed that proximal colonic digesta total SCFA pool was greatest in the pigs fed Himalaya 292 (Table 8) but this difference was significant only compared with oat bran. In the mid- and distal colon, SCFA pools were similar in the pigs fed wheat bran and Namoi, and significantly greater in the pigs fed Namoi than in those fed Himalaya 292. In the distal colon, pools in both wheat-bran and Namoi groups were equally and significantly greater than in the other two groups. As expected, differences in acetate pools followed very similar patterns to those of total SCFA. As with acetate, the pools of propionate were higher in the proximal large bowel of the pigs fed Himalaya 292 (and significantly greater than in those fed oat bran) (Table 8). In contrast, in the distal colon there were lower values in the pigs fed Himalaya 292 or oat bran compared with Namoi while in the mid-colon propionate pools were smaller in the pigs fed Himalaya $292 \mathrm{com}-$ pared with Namoi. Broadly similar differences were obtained with butyrate (Table 8 ).

\section{Proximal colonic bacteria}

Total anaerobe numbers were highest in the pigs fed Himalaya 292 but the difference was significant only against wheat bran (Table 9). Aerobe numbers were significantly lower in the animals fed Namoi than in all other groups. There were no treatment effects on numbers of Lactobacilli or Bifidobacteria. Digesta total coliform and E. coli numbers were lowest in the pigs fed Namoi than in all of the other groups and these differences were significant against all other treatments for coliforms and against Himalaya 292 and oat bran for E. coli (Table 9).

\section{Discussion}

The genetic change in Himalaya 292 leads to substantial alterations in starch content and composition (Morell et al. 2003; Topping et al. 2003), which are retained under different growing conditions (MK Morell, personal communication). In particular, the starch content of Himalaya 292 grain is as low as $18 \%$, with approximately $70 \%$ of the starch present as amylose compared with approximately 50 and $25 \%$ respectively for its Himalaya parent (Morell et al. 2003). The raised amylose content appears to be due largely to a much lower content of amylopectin (Morell et al. 2003). These differences lead to substantial changes in functional properties, including crystallinity and gelatinisation (Morell et al. 2003). In addition, there are other changes in composition, for example, an increase in total and soluble NSP (including $\beta$-glucan), which could influence health-related outcomes (Topping et al. 2003). These include the lowering of plasma cholesterol and the reduction of glycaemic index, well-established effects of soluble NSP (Wursch \& Pi-Sunyer, 1997; Brown et al. 1999; Kerckhoffs et al. 2002; Wolever, 2003). It is 
A. R. Bird et al.
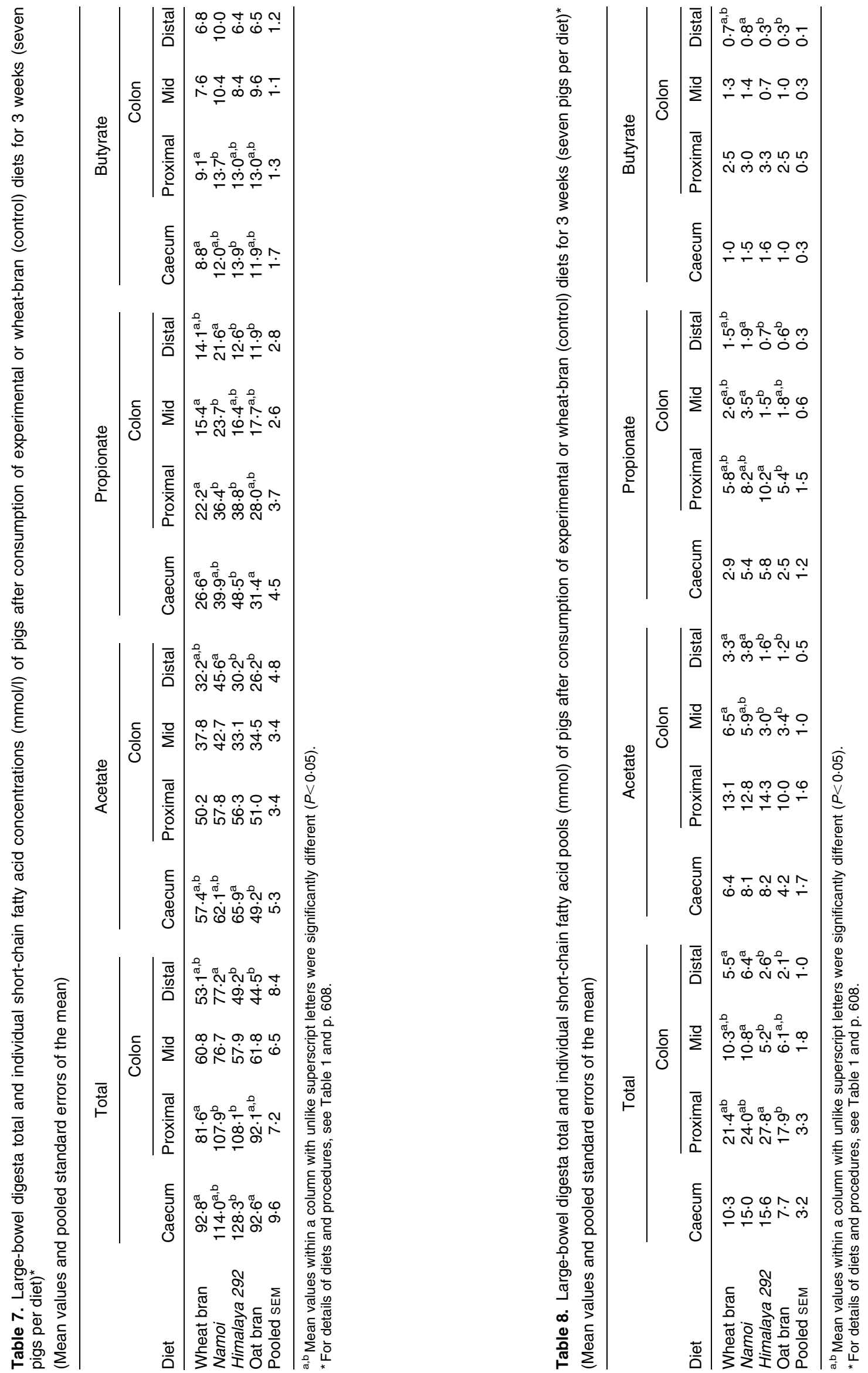
Table 9. Bacterial populations ( $\log _{10}$ colony-forming units/g) in the proximal colon contents of pigs after consumption of experimental or wheat-bran (control) diets for 3 weeks (seven pigs per diet)*

(Mean values and pooled standard errors of the mean)

\begin{tabular}{lcccccc}
\hline Diet & Anaerobes & Aerobes & Lactobacilli & Bifidobacteria & Total coliforms & Escherichia coli \\
\hline Wheat bran & $9.03^{\mathrm{a}}$ & $8.02^{\mathrm{a}}$ & 7.93 & 6.84 & $8.00^{\mathrm{a}}$ & $7.85^{\mathrm{a}, \mathrm{b}}$ \\
Namoi & $9.14^{\mathrm{a}, \mathrm{b}}$ & $7.55^{\mathrm{b}}$ & 7.39 & 6.27 & $7.47^{\mathrm{b}}$ & $7.31^{\mathrm{a}}$ \\
Himalaya 292 & $9.34^{\mathrm{b}}$ & $8.25^{\mathrm{a}}$ & 8.11 & 6.75 & $8.23^{\mathrm{a}}$ & $8.14^{\mathrm{b}}$ \\
Oat bran & $9.4^{\mathrm{a}, \mathrm{b}}$ & $8.34^{\mathrm{a}}$ & 7.49 & 7.31 & $8.22^{\mathrm{a}}$ & $8.11^{\mathrm{b}}$ \\
Pooled SEM & 0.07 & 0.15 & 0.36 & 0.46 & 0.18 & 0.20 \\
\hline
\end{tabular}

${ }^{a, b}$ Mean values within a column with unlike superscript letters were significantly different $(P<0.05)$.

* For details of diets and procedures, see Table 1 and p. 608.

important to establish that these components in Himalaya 292 retained their physiological attributes after heat stabilisation and milling and the present experiment established that, in pigs, Himalaya 292 was as effective as a commercial barley and oat bran in this regard. As expected from human (Newman et al. 1989; Kestin et al. 1990; McIntosh et al. 1991), pig (Topping et al. 1993) and rodent (Jackson et al. 1994) studies, plasma total and non-HDL-cholesterol (VLDL + intermediate-density lipoprotein + LDL) were highest in our pigs fed wheat bran and lowest in pigs fed oat-bran and Himalaya 292 diets at equivalent intakes of NSP. Importantly, Himalaya 292 and the commercial Namoi barley were at least as effective as oat bran. Thus, the mutation in the starch synthetic pathway does not seem to have altered the effectiveness of the heat-treated and milled grain in lowering cholesterol. As noted, it is thought that this is effected largely through $\beta$-glucan. The diet in the present study was low in cholesterol so that the observed changes are most probably largely due to endogenous steroid metabolism rather than in cholesterol absorption. Although they were not measured in the present experiment, it is probable that there was an increase in faecal bile acid and neutral sterol excretion in the pigs fed the barley and oat diets. This would lead to a compensatory increase in cholesterol catabolism and a fall in plasma concentrations (Prentice et al. 1982; Zhang et al. 1990; Lia et al. 1995). However, it must be recognised that barley contains other components that may be involved since brewer's spent barley grain, which is depleted in soluble NSP, also lowers plasma cholesterol in human subjects (Zhang et al. 1991; Lupton et al. 1994). The relative contributions of these components to the effects of Himalaya 292 on plasma lipids remain to be established. Lowered serum HDL-cholesterol and raised TAG are respectively positive risk factors for CHD (Coughlan \& Sorrentino, 2000; Black, 2003) so the lack of unwanted effects of the Himalaya 292 diet on HDL-cholesterol and TAG is potentially important if it can also be demonstrated in human subjects.

Faecal SCFA concentrations were generally similar in the four experimental groups. This is not altogether surprising since NSP would be a major determinant of largebowel SCFA and, in the present study, the cereal products were fed in diets formulated to provide equal amounts of these polysaccharides. Nevertheless, the faecal and largebowel data suggest that there were differences between treatments in SCFA production. In particular, large-bowel digesta and faecal $\mathrm{pH}$ values were uniformly higher in the pigs fed wheat bran than in the other three groups, which is consistent with less SCFA production in the former. Wheat bran is of relatively low fermentability, which helps to account for its relative superiority as a faecal bulking and laxating agent (Topping \& Clifton, 2001); this would account for the greater large-bowel digesta mass in the pigs fed the wheat-bran diet. A study in human subjects has shown that the consumption of wheat bran raises faecal SCFA (Lewis \& Heaton, 1997). This occurs through diminished absorption, with no apparent change in production and explains the present faecal $\mathrm{pH}$ and SCFA data. Further, it accounts for the differences in the proportions of the three SCFA between the pigs fed wheat bran and those fed the other diets. As in previous studies by us (Marsono et al. 1993; Topping et al. 1993) and others (Bach-Knudsen et al. 1991), large-bowel SCFA were high in the proximal large bowel and fell towards the distal colon. This distribution is similar to that seen in human surgical patients (Mitchell et al. 1985) and reflects the predominance of SCFA production in the caecum and proximal colon and the decline of fermentation (due to substrate depletion and colonic uptake) on passage of the faecal stream. Less than $10 \%$ of the SCFA produced are excreted in the faeces, which means that relatively small changes in transit translate to disproportionate variations in their excretion (Lewis \& Heaton, 1997).

Although the distributional profile of SCFA within the large bowel was broadly similar between groups, there were differences by sampling site. The distribution of SCFA in the bowel of the pigs fed the Namoi diet was similar to that in those fed wheat bran, and the higher values in the distal colon compared with other regions may reflect either differences in transit or fermentation. The latter appears the more probable, given the lower $\mathrm{pH}$ values. The level of inclusion of Namoi in the diet was more than double that of the other cereals and it is possible that there was a greater contribution of RS to large-bowel fermentation in this group. A more direct comparison can be made between Himalaya 292 and oat bran, which had similar levels of inclusion in the diet, and the higher SCFA in the former support our analytical and rat data indicating greater RS in Himalaya 292 (Topping et al. 2003; Bird et al. 2004). However, the fact that the differences were confined to the proximal large bowel suggests greater fermentation but slower transit. Martinez-Puig 
et al. (2003) reported recently that a high-RS (as raw potato starch) diet had similar effects in pigs. Conversely, we have reported that RS (as a high-amylose maize starch) appears to be fermented rapidly in pigs relative to passage of the faecal stream (Topping et al. 1997). Indeed, it has been shown in rats (Morita et al. 1999) and pigs (Govers et al. 1999) that for effective transport of SCFA to the distal colon, the presence of faecal bulking by NSP seems necessary. This appears to be the case here despite the fact that NSP were equivalent in all diets.

SCFA are known to affect intestinal morphology and their intravenous infusion in rats reverses the colonic atrophy induced by the feeding of low-fibre diets (Topcu et al. 2002). Diets high in fibre or RS increase large-bowel organ dimensions. For RS this is either as weight (in rats; Goodlad \& Mathers, 1990) or length (in pigs; Topping et al. 1997; Martinez-Puig et al. 2003) but it is unclear whether these differences are an effect of animal species or RS type. The apparent paradox between large-bowel hypertrophy (which might have been expected to increase the risk of neoplasms) and diminished risk of malignancy has been linked to butyrate and has been called 'the butyrate paradox' (Velazquez et al. 1996). It seems that this diminished risk reflects the effects of butyrate and, to a lesser extent, propionate in promoting a normal cell phenotype. The relative lack of difference in pool size of these important SCFA between treatments may be the reason for the present findings where neither large-bowel length nor mass was affected by diet.

The importance of the interaction between indigestible dietary carbohydrates and the large-bowel microflora is well recognised and prebiotics have been developed to stimulate the growth of those intestinal bacteria that are thought to promote human health (Gibson \& Roberfroid, 1995). Some forms of RS, such as high-amylose maize starches, are prebiotics and stimulate large-bowel and faecal lactic acid bacteria but other types are not (Bird et al. 2000a). We did not detect any consistent differences in faecal and proximal colonic bifidobacteria and lactobacilli and, hence, any prebiotic action of the Himalaya 292 diet in the present experiment. However, the finding of significantly lower faecal bifidobacteria numbers in the Namoi group before adaptation to the experimental diets is a potential confounder and is unexplained. The possible influence of differences between groups at baseline is reflected also in the borderline difference in the number of faecal anaerobes between the Namoi and Himalaya 292 groups during the initial adaptation period. Non-selection can be overcome by using cross-over designs rather than the parallel design used in the present study. Also, the classical culture-based approach to analyse the enteric flora has well-recognised limitations. It is possible that the use of molecular tools, which have greater sensitivity and precision, may have yielded more information on the prebiotic potential of Himalaya 292 and the other cereals. The higher numbers of faecal anaerobes in pigs fed the Himalaya 292 and oat-bran diets are consistent with greater fermentation through substrate provision. The same is true for the difference in bacterial numbers in the proximal colon. However, it appears that the Namoi diet inhibited bacterial growth, as numbers were lowest in this group.
In summary, the present study has demonstrated a number of favourable changes of indices of cardiovascular and bowel health in pigs consuming a diet containing the novel barley cultivar Himalaya 292. Further studies are planned to evaluate these properties in human subjects.

\section{References}

Anderson JW, Davidson MH, Blonde L, Brown WV, Howard WJ, Ginsberg H, Allgood LD \& Weingand KW (2000) Long-term cholesterol-lowering effects of psyllium as an adjunct to diet therapy in the treatment of hypercholesterolemia. Am J Clin Nutr 71, 1433-1438.

Asp N-G (1992) Resistant starch. Eur J Clin Nutr 46, Suppl. 2, S1.

Bach-Knudsen KE, Jensen BB, Andersen JO \& Hansen I (1991) Gastrointestinal implications in pigs of wheat and oat fractions. 2. Microbial activity in the gastrointestinal tract. Br J Nutr $\mathbf{6 5}$, 233-248.

Bird AR, Brown IL \& Topping DL (2000a) Starches, resistant starches, the gut microflora and human health. Curr Issues Intest Microbiol 1, 25-37.

Bird AR, Flory C, Davies DA, Usher S \& Topping DL (2004) A novel barley cultivar (Himalaya 292) with a specific gene mutation in starch synthase IIa raises large bowel starch and short chain fatty acids in rats. J Nutr 134, 831-835.

Bird AR, Hayakawa T, Marsono Y, Gooden JM, Record IR, Correll RL \& Topping DL (2000b) Coarse brown rice increases fecal and large bowel short-chain fatty acids and starch but lowers calcium in the large bowel of pigs. J Nutr 130, 1780-1787.

Black DM (2003) Therapeutic targets in cardiovascular disease: a case for high-density lipoprotein cholesterol. Am J Cardiol 91, 40E-43E.

Borum ML (2001) Constipation: evaluation and management. Prim Care 28, 577-590.

Brown L, Rosner B, Willett WW \& Sacks FM (1999) Cholesterol-lowering effects of dietary fiber: a meta-analysis. Am J Clin Nutr 69, 30-42.

Coughlan BJ \& Sorrentino MJ (2000) Does hypertriglyceridemia increase risk for CAD? Growing evidence suggests it plays a role. Postgrad Med 108, 77-84.

Gibson GR \& Roberfroid MB (1995) Dietary modulation of the human colonic microbiota: introducing the concept of prebiotics. J Nutr 125, 1401-1412.

Goodlad JS \& Mathers JC (1990) Large bowel fermentation in rats given diets containing raw peas (Pisum sativum). $\mathrm{Br} J$ Nutr 64, 569-587.

Govers MJ, Gannon NJ, Dunshea FR, Gibson PR \& Muir JG (1999) Wheat bran affects the site of fermentation of resistant starch and luminal indexes related to colon cancer risk: a study in pigs. Gut $\mathbf{4 5}, 840-847$.

Jackson KA, Suter DA \& Topping DL (1994) Oat bran, barley and malted barley lower plasma cholesterol relative to wheat bran but differ in their effects on liver cholesterol in rats fed diets with and without cholesterol. J Nutr 124, 1678-1684.

Jenkins DJ, Kendall CW, Vuksan V, et al. (2002) Soluble fiber intake at a dose approved by the US Food and Drug Administration for a claim of health benefits: serum lipid risk factors for cardiovascular disease assessed in a randomized controlled crossover trial. Am J Clin Nutr 75, 834-839.

Kerckhoffs DA, Brouns F, Hornstra G \& Mensink RP (2002) Effects on the human serum lipoprotein profile of betaglucan, soy protein and isoflavones, plant sterols and stanols, garlic and tocotrienols. J Nutr 132, 2494-2505.

Kestin M, Moss R, Clifton PM \& Nestel PJ (1990) Comparative 
effects of three cereal brans on plasma lipids, blood pressure, and glucose metabolism in mildly hypercholesterolemic men. Am J Clin Nutr 52, 661-666.

Lewis SJ \& Heaton KW (1997) Increasing butyrate concentration in the distal colon by accelerating intestinal transit. Gut $\mathbf{4 1}$, 245-251.

Lia A, Hallmans G, Sandberg AS, Sundberg B, Aman P \& Andersson H (1995) Oat $\beta$-glucan increases bile acid excretion and a fiber-rich barley fraction increases cholesterol excretion in ileostomy subjects. Am J Clin Nutr 62, 1245-1251.

Lupton JR, Robinson MC \& Morin JL (1994) Cholesterol-lowering effect of barley bran flour and oil. J Am Diet Assoc 94, $65-70$.

McIntosh GH, Whyte J, McArthur R \& Nestel PJ (1991) Barley and wheat foods: influence on plasma cholesterol concentrations in hypercholesterolemic men. Am J Clin Nutr 53, $1205-1209$.

Marquart L, Slavin JL \& Fulcher RG (2002) Whole-grain Foods in Health and Disease. St Paul, MN: American Association of Cereal Chemists Inc.

Marsono Y, Illman RJ, Clarke JM, Trimble RP \& Topping DL (1993) Plasma lipids and large bowel volatile fatty acids in pigs fed on white rice, brown rice and rice bran. $\mathrm{Br} J \mathrm{Nutr}$ 70, 503-513.

Martinez-Puig D, Perez JF, Castillo M, Andaluz A, Anguita M, Morales J \& Gasa J (2003) Consumption of raw potato starch increases colon length and fecal excretion of purine bases in growing pigs. $J$ Nutr 133, 134-139.

Mitchell BL, Lawson MJ, Davies M, Kerr-Grant A, Roediger WEW, Illman RJ \& Topping DL (1985) Volatile fatty acids in the human intestine: studies in surgical patients. Nutr Res 5, 1089-1092.

Morell MK, Kosar-Hashemi B, Cmiel M, Samuel MS, Chandler P. Rahman S, Buleon A, Batey IL \& Li Z (2003) Barley sex6 mutants lack starch synthase IIa activity and contain a starch with novel properties. Plant J 34, 173-185.

Morita T, Kasaoka S, Hase K \& Kiriyama S (1999) Psyllium shifts the fermentation site of high-amylose cornstarch toward the distal colon and increases fecal butyrate concentration in rats. $J$ Nutr 129, 2081-2087.

National Health and Medical Research Council (1997) Australian Code of Practice for the Care and Use of Animals for Scientific Purposes. Canberra, Australia: National Health and Medical Research Council.

Newman RK, Lewis SE, Newman CW, Boik RJ \& Ramage RT (1989) Hypocholesterolemic effect of barley foods on healthy men. Nutr Rep Int 39, 749-760.

Pachenari A, Conway PL \& Playne MJ (2001) Bifidus-blood agar a differentiating medium for the isolation and enumeration of bifidobacteria from faecal samples. Biosci Microflora 20, 85-88.

Prentice N, Qureshi AA, Burger WC \& Elson CE (1982)
Response of hepatic cholesterol, fatty acid synthesis and activities of related enzymes to rolled barley and oats in chickens. Nutr Rep Int 26, 597-604.

Roe M, Brown J, Faulks R \& Livesey G (1996) Is the rat a suitable model for humans for studies of cereal digestion? Eur $J$ Clin Nutr 50, 710-712.

Spiller GA (2001) Definitions of dietary fiber. In CRC Handbook of Dietary Fiber in Human Nutrition, pp. 9-10 [GA Spiller, editor]. Boca Raton, FL: CRC Press.

Stephen AM, Haddad AC \& Phillips SF (1983) Passage of carbohydrate into the colon. Direct measurements in humans. Gastroenterology 85, 589-595.

Topcu O, Karaday K, Kuzu MA, Ulukent S, Erkek B \& Alacayir I (2002) Enteral and intraluminal short-chain fatty acids improves ischemic left colonic anastomotic healing in the rat. Int J Colorectal Dis 17, 171-176.

Topping DL \& Clifton PM (2001) Short-chain fatty acids and human colonic function: roles of resistant starch and nonstarch polysaccharides. Physiol Rev 81, 1031-1064.

Topping DL, Gooden JM, Brown IL, Biebrick DA, McGrath L, Trimble RP, Choct M \& Illman RJ (1997) A high amylose (amylomaize) starch raises proximal large bowel starch and increases colon length in pigs. $J$ Nutr 127, 615-622.

Topping DL, Illman RJ, Clarke JM, Trimble RP, Jackson KA \& Marsono Y (1993) Dietary fat and fiber alter large bowel and portal venous volatile fatty acids and plasma cholesterol but not biliary steroids in pigs. J Nutr 123, 133-143.

Topping DL, Morell MK, King RA, Li Z, Bird AR \& Noakes M (2003) Resistant starch and health - Himalaya 292, a novel barley cultivar to deliver benefits to consumers. Starch 55, 539-545.

Truswell AS (2002) Cereal grains and coronary heart disease. Eur J Clin Nutr 56, 1-14.

Velazquez OC, Lederer HM \& Rombeau JL (1996) Butyrate and the colonocyte. Implications for neoplasia. Dig Dis Sci 41, 727-739.

Wolever TM (2003) Carbohydrate and the regulation of blood glucose and metabolism. Nutr Rev 61, S40-S48.

Wursch P \& Pi-Sunyer FX (1997) The role of viscous soluble fiber in the metabolic control of diabetes. A review with special emphasis on cereals rich in beta-glucan. Diabetes Care 20, $1774-1780$

Zhang JX, Bergman F, Hallmans G, Johansson G, Lundin E, Stenling R, Theander O \& Westerlund E (1990) The influence of barley fibre on bile composition, gallstone formation, serum cholesterol and intestinal morphology in hamsters. APMIS 98, $568-574$.

Zhang JX, Lundin E, Andersson H, Bosaeus I, Dahlgren S, Hallmans G, Stenling R \& Aman P (1991) Brewer's spent grain, serum lipids and fecal sterol excretion in human subjects with ileostomies. J Nutr 121, 778-784. 